\title{
Panorama actual y tendencias recientes de refugiados y solicitantes de refugio en el siglo XXI: México en el entorno mundial
}

Rodolfo Casillas R. FLACSO, México

Resumen: De 2000 a 2017, los refugiados, quienes solicitan refugio y la respuesta de los gobiernos, han tenido comportamientos distintos. Lo anterior genera efectos diversos en los países, las regiones y en los continentes, sean lugar de origen o de asilo de solicitantes de refugio. Durante estos años, Canadá y Estados Unidos fueron grandes receptores de solicitudes de refugio. Por su parte, México recibió cantidades crecientes de solicitudes, aunque en un número menor a los países antes mencionados. Las cifras que se presentan en este texto, los pesos relativos de los procesos de refugio a escala mundial, regional y nacional, invitan a revisar y comparar la congruencia entre los discursos oficiales y las políticas reales que han adoptado los países de la región para generar una actuación y un marco de acción, en común, que haga factible la solidaridad con quienes solicitan refugio y el orden público de las naciones.

Palabras claves: solicitud de refugio, solicitud de refugio aceptada, solicitud de refugio rechazada, nivel mundial, nivel continental, nivel regional, nivel nacional.

Abstract: From 2000 to 2017, refugees and asylum flows have fluctuated greatly, generating ripple effects in countries, regions, and entire continents. These effects are felt deeply in countries of origin, as well as countries of destination and transit. From 2000 to 2017, the period that this article will be examining, Canada and the United States were the largest recipients of asylum requests in North America. Mexico received a growing number of requests, although to a lesser extent than its neighbors to the North. The following analysis situates refugee and asylum rates on a regional and global scale and invites us to examine and compare how the official discourse conforms to the actual policies that have been adopted in Central and North America, as well as examines interventions and frameworks for action that could promote both solidarity and public order. 
Keywords: Refugee and asylum requests, refugee and asylum approvals, worldwide, regional level.

\section{Introducción}

El número de personas que se ven forzadas a desplazarse, dentro o fuera de las fronteras de su país, ha aumentado en el mundo. Para finales de 2017, 68,5 millones de personas se vieron obligadas a huir de sus hogares y buscar protección dentro o fuera de su país. En este proceso de desplazamiento forzado, una persona puede convertirse en solicitante de refugio o en refugiada, entre otros estatus internacionales. De esos 68,5 millones de personas desplazadas forzadamente, 25,4 millones fueron reconocidas como refugiadas $-19,9$ millones de refugiados bajo el mandato del Alto Comisionado de Naciones Unidas para los Refugiados (ACNUR) y 5,4 millones registrados por el mismo organismo (ACNUR, 2017); queda por saber qué fue de los 43,1 millones de personas no reconocidas.

Las múltiples causas del proceso migratorio implican condiciones y circunstancias diversas para llevarse a cabo, y dan lugar a distintos flujos de personas migrantes (Organización Internacional para las Migraciones [OIM], 2015), a determinados procedimientos en los países en que se presentan las peticiones de refugio, en este caso, y a ulteriores procesos nacionales e internacionales. Desde esta perspectiva, la presentación de solicitud de refugio y su resultado es sólo una parte de un proceso más largo y complejo, pero de gran importancia: puede significar vida o muerte, en caso extremo.

Este documento se centra en el análisis de las cifras de solicitantes de refugio, así como del número de solicitudes aceptadas, con particular interés en los procesos ocurridos en el centro y norte de América, con el fin de destacar lo que ocurre en México. No se pretenda una discusión de corte jurídico sobre los contenidos, alcances o las distintas interpretaciones que las autoridades gubernamentales pueden dar al marco legal (Asylum Access México, 2019; Kerwin, H., 2018; Pew Research Center, 2017; Triandafyllidou, 2017; y Triandafyllidou y Mantanika, 2017), sino analizar las series estadísticas para observar su peso relativo en los distintos ámbitos de interés en este caso.

La emergencia de refugiados durante el período 2015-2017, en Europa, muestra que distinguir los contenidos específicos de los flujos mixtos (migrantes económicos, solicitantes de refugio, etc.) se vuelve cada vez más importante para atenderlos y conocer las motivaciones person- 
ales para salir de su país de origen. "La línea que separa al asilo de los flujos migratorios es cada vez más difusa, incluso en el terreno, ya que la gente viaja por las mismas rutas y usa las mismas redes de contrabando de personas para cruzar ilegalmente las fronteras externas de la Unión Europea (UE)" (Triandafyllidou y Mantanika: 2017, 9).

Aunque se trata de dos problemas distintos (solicitantes de refugio y flujos migratorios mixtos), la idea de analizar en esta ocasión qué pasa con quienes gestionan refugio tiene que ver, en esencia, con el comportamiento estadístico de ese flujo a distinta escala, del peso relativo que un proceso tiene frente a otros en territorios distintos, etc., así como dejar registro del volumen de solicitantes que cada año no recibe una respuesta favorable a su petición, como objetivo subordinado, una población rechazada que muy posiblemente engrose otro flujo migratorio internacional como segunda opción.

En el primer apartado se posiciona a México en el escenario histórico y actual de Centroamérica, además se caracteriza la población solicitante de refugio en este país en el año 2017. En un segundo momento, se analizan las tendencias de las cifras de solicitantes de refugio en el continente americano $y$, de manera particular, en Estados Unidos y Canadá. En una tercera sección se analiza en el siglo XXI el comportamiento de los solicitantes de refugio y refugiados a nivel mundial. Finalmente, se presentan las conclusiones más relevantes.

\section{Las solicitudes de refugio en México, 2000-2017}

\section{De acuerdo con el Alto} Comisionado de las Naciones Unidas para los Refugiados (ACNUR), los solicitantes de refugio en México tuvieron un incremento notable entre 2000 y 2017 , de 277 a $14,528^{1}$, en un movimiento de menos a más demandantes, que presenta cifras mayores, si se toma como base el año 2000, para los años 2016 y 2017, como se observa en el Cuadro 1. Aparte de la firma y ratificación de protocolos y convenciones en materia de refugio por parte del Estado mexicano, las autoridades mexicanas cuentan con distintas disposiciones legales e instrumentos jurídicos emanados del poder Legislativo, entre los que destacan la Ley de Migración de 2011, y reformas posteriores en 2017; la Ley sobre Refugiados, Protección Complementaria y Asilo Político de 2014;y el Reglamento de la Ley Sobre Refugiados y Protección Complementaria de 2012 (Congreso de la Unión de los Estados Unidos Mexicanos, 2012, 2014 y 2017). 
Con respecto a las solicitudes aceptadas, a pesar de su leve incremento en los dos últimos decenios, México ha rechazado en promedio tres de cada cinco solicitantes de refugio en el siglo XXI. En los últimos años el total de solicitudes aceptadas en 2017 disminuyó en $58.49 \%$ en relación con el total de solicitudes de refugio aceptadas en $2016(3,282)$, mientras que se recibieron 14,528 solicitudes ( $59.82 \%$ más que en 2016) (Trejo y Suárez, 2016).
Dicho de otra forma, México recibió en 2017, 40 solicitudes en promedio por día, una cifra manejable para una dependencia federal, aunque sea llamativa si se considera que en 2000 recibía menos de una por día (0.75). Y, en términos de volumen, 14 , 528 es una cifra que, en términos relativos, dista mucho de ser significativa para una población total en el país de poco más de 120 millones de habitantes.

Cuadro 1. Solicitudes de refugio recibidas y aceptadas en México, 2000-2017

\begin{tabular}{|l|l|l|}
\hline \multicolumn{1}{|c|}{ AÑO } & \multicolumn{1}{c|}{ RECIBIDAS } & ACEPTADAS \\
\hline 200 & 277 & 78 \\
\hline 2001 & 415 & 142 \\
\hline 2002 & 257 & 69 \\
\hline 2003 & 275 & 40 \\
\hline 2004 & 404 & 67 \\
\hline 2005 & 167 & 131 \\
\hline 2006 & 479 & 82 \\
\hline 2007 & 374 & 79 \\
\hline 2008 & 317 & 101 \\
\hline 2009 & 680 & 123 \\
\hline 2010 & 1039 & 223 \\
\hline 2011 & 753 & 259 \\
\hline 2012 & 811 & 242 \\
\hline 2013 & 1296 & 266 \\
\hline 2014 & 1524 & 0 \\
\hline 2015 & 2423 & 929 \\
\hline 2016 & 8732 & 3260 \\
\hline 2017 & 14528 & 2806 \\
\hline & & \\
\hline
\end{tabular}

Fuente: Alto Comisionado de Naciones Unidas para los Refugiados (ACNUR). Estadísticas de población. Series de tiempo. Disponible en: http://popstats.unhcr. org/en/persons_of_concern 
Los solicitantes de refugio en México, en su mayoría, provienen de uno de los tres países del norte de Centroamérica: Honduras, El Salvador y Guatemala. Los procesos políticos y la delincuencia urbana presente en estos tres países son algunos de los factores que llevan a su población a solicitar protección en distintos escenarios (Martínez,
2010 y 2016). Por otro lado, debido a la crisis económica y política de Venezuela, su población es uno de los colectivos con mayor número de solicitudes de refugio en México en los dos últimos años. Cuba y algunos países del Caribe como Haití son otros lugares de origen de los solicitantes de refugio (Gráfica 1 ).

\section{Gráfica 1. Solicitudes de refugio recibidas en México, según principales países y regiones de}

origen, 2000-2018

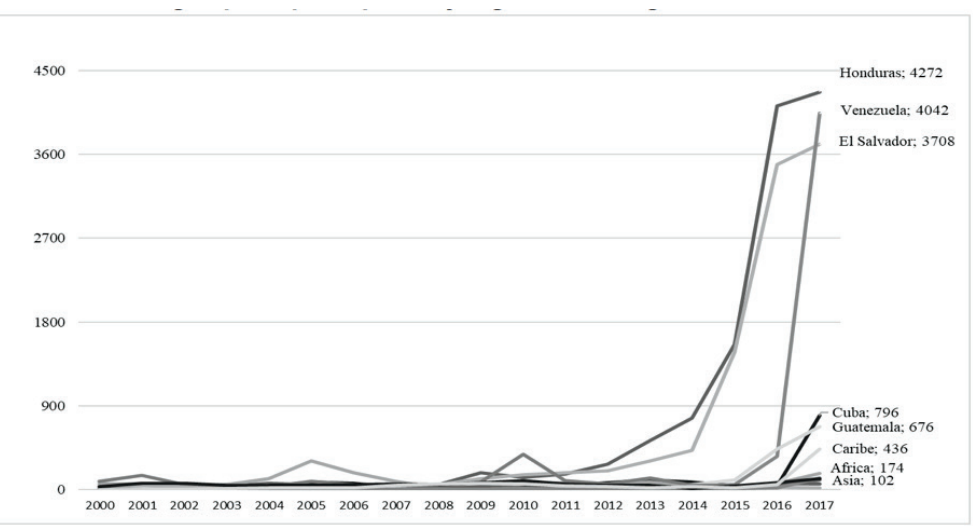

Fuente: Alto Comisionado de Naciones Unidas para los Refugiados (ACNUR). Estadísticas de población. Series de tiempo. Disponible en: http://popstats. unhcr.org/en/persons_of_concern

En relación con los principales países de solicitantes de refugio a México en $2017^{2}$, Honduras y Venezuela ocupan los dos primeros sitios: 4,272 solicitudes de hondureños $(29.27 \%$ del total) y 4,042 solicitudes de venezolanos $(27.69 \%$ del total). El Salvador ocupa el tercer lugar con un total de 3,708 solicitudes (25.40\% del total), mientras que Guatemala ocupó el quinto sitio con 676 (0.20\% del total). 
Cuadro 2. Principales países de solicitantes de refugio a México, según estado de la solicitud, 2017

\begin{tabular}{|c|c|c|c|c|}
\hline Pais & Solicitantes & $\begin{array}{c}\text { Solicitantes que } \\
\text { concluyeron } \\
\text { procedimientos }\end{array}$ & Reconocidos & No reconocidos \\
\hline Honduras & 4,272 & 1,537 & 378 & 767 \\
\hline Venezuela & 4,042 & 912 & 907 & 5 \\
\hline El Salvador & 3,708 & 1,509 & 525 & 543 \\
\hline Cuba & 796 & 153 & 17 & 130 \\
\hline Guatemala & 676 & 239 & 55 & 116 \\
\hline
\end{tabular}

Fuente: Comisión Mexicana de Ayuda a Refugiados (Comar), Estadísticas 2017.

Llama la atención que, a pesar de que Honduras fue el país que presentó el mayor número de solicitudes de refugio a México, las solicitantes de Venezuela fueron las más aceptadas: 907 (47.56\% del total). Las procedencias de otras solicitudes aceptadas fueron: 525 salvadoreñas (27.53\%), 378 hondureñas (19.82\%), 55 guatemaltecas $(2.88 \%)$ y únicamente 17 cubanas ( $0.89 \%)$. Honduras fue el país con el mayor número de solicitudes no aceptadas durante 2017: 767. Dadas las diferencias, públicas y notorias, entre las cancillerías mexicana y venezolana, no es descartable un componente político en el otorgamiento de un mayor de visas por parte del gobierno mexicano a las solicitudes provenientes de ese país.

El Cuadro 3 describe algunos rasgos sociodemográficos relevantes de los solicitantes de refugio en
México para el año 2017. Del total de solicitudes recibidas en 2017, 5,876 fueron de mujeres (40.36\%) y 8,720 fueron de hombres (59.74\%). Sin embargo, fueron aceptadas 875 solicitudes por parte de mujeres y 1,032 de hombres. Es decir, del total de solicitudes aceptadas en el país durante 2017, el 5.99\% del total de las solicitudes de mujeres fueron aceptadas, mientras que un $7.07 \%$ del total de las de hombres recibió aceptación.

Los niños, niñas y adolescentes (NNA) también representaron una cifra diferenciable del total de solicitudes de refugio enviadas a México durante 2017: 259 solicitudes (1.77\% del total de recibidas). De ellas, únicamente fueron aceptadas 36 (1.89\%), mientras que 53 solicitudes fueron no reconocidas (3.21\% del total de las no reconocidas). Del total de solicitudes de 
refugio de NNA, 29.73\% correspondieron a niñas y adolescentes mujeres, mientras que $70.27 \%$ a niños $y$ adolescentes hombres. Por su parte, del total de solicitudes aceptadas de NNA, 32.69 fueron de niñas y adolescentes mujeres, mientras que $61.11 \%$ fueron de niños y adolescentes hombres.

Los países con mayor número de solicitudes de refugio de NNA presentadas a México durante 2017 fueron Honduras, El Salvador y Guatemala; los tres países del norte centroamericano, de donde también procede el mayor volumen de migrantes internacionales de paso que detiene migración mexicana (aproximadamente el $96 / 97 \%$ del total anual, promedio, en lo que va del siglo XXI) (Segob, 2017). Honduras fue el país con mayor número de solicitudes enviadas: 153 (59.07\%), le sigue El Salvador con 62 (23.93\%), mientras que Guatemala sólo envió 21 solicitudes (8.10\%).
El comportamiento de las principales nacionalidades solicitantes de refugio de NNA aceptadas en México, durante 2017, corresponde al señalado de los países del norte centroamericano en relación con la migración internacional de paso por suelo mexicano. Honduras, Guatemala y El Salvador han sido los principales países con flujos migratorios que transitan por México, con destino final en Estados Unidos. Si bien la cifra de solicitudes de refugio de NNA aceptadas, en ese año, no es muy elevada, representa una invitación a revisar los protocolos de atención y protección para este grupo poblacional. Ello ayudaría a diferenciar componentes del flujo migratorio mixto que, desde una perspectiva procesual, se ha mantenido constante, cuando no al alza, nutrido por migrantes económicos, solicitantes rechazados de refugio, por expulsados de Estados Unidos que quieren retornar a ese país, etc. Es decir, avanzar en diferenciar flujos que se mezclan en el trayecto para su atención diferenciada. 
Cuadro 3. Indicadores sociodemográficos según estado de la solicitud de refugio en México, 2017.

\begin{tabular}{|c|c|c|c|c|}
\hline $\begin{array}{l}\text { Indicadores } \\
\text { sociales }\end{array}$ & Solicitudes & $\begin{array}{l}\text { Solicitudes } \\
\text { completas }\end{array}$ & Aprobadas & No aprobadas \\
\hline \multicolumn{5}{|l|}{ Sexo (\%) } \\
\hline Mujeres & 59.74 & 41.68 & 45.87 & 35.46 \\
\hline Hombres & 40.26 & 58.32 & 54.13 & 64.54 \\
\hline Total & 14,596 & 4,475 & 1,907 & 1,650 \\
\hline \multicolumn{5}{|c|}{ Niños y adolecentes por sexo (\%) } \\
\hline $\begin{array}{l}\text { Niños y } \\
\text { adolecentes } \\
\text { (Mujeres) }\end{array}$ & 29.73 & 32.69 & 38.89 & 26.42 \\
\hline $\begin{array}{l}\text { Niños y } \\
\text { adolecentes } \\
\text { (Hombres) }\end{array}$ & 70.27 & 67.31 & 61.11 & 73.58 \\
\hline Total & 259 & 104 & 36 & 53 \\
\hline \multicolumn{5}{|c|}{ Lugar de origen de los niños y adolescentes (\%)* } \\
\hline Honduras & 64.83 & 56.26 & 38.71 & 66.67 \\
\hline El Salvador & 26.27 & 30.21 & 54.84 & 15.69 \\
\hline Guatemala & 8.90 & 13.54 & 6.45 & 17.65 \\
\hline Total & 236 & 96 & 31 & 51 \\
\hline
\end{tabular}

Fuente: Comisión Mexicana de Ayuda a Refugiados (Comar), Estadísticas 2017.

\section{Solicitudes de refugio en el continente americano}

En este apartado se analiza desde una escala regional las solicitudes y aceptaciones de refugio en Estados Unidos, Canadá, México y Centroamérica. El análisis permite justipreciar el papel de México como país receptor o no de solicitantes internacionales de refugio.

De 2000 a 2017 el continente americano recibió un total de
2,139,616 solicitudes de refugio (10.76\% del total mundial) y aceptó un total de 610,498 de esas solicitudes $(14.61 \%$ del total mundial); $1,529,118$ de personas rechazadas engrosaron probablemente algún otro flujo migratorio internacional o buscaron alguna forma fuera de registro gubernamental para quedarse en el lugar de asilo deseado, por incierta que sea esa 
forma de permanecer (Instituto Técnico Autónomo de México [ITAM], 2014). En relación con las tasas de crecimiento del número de solicitudes recibidas y aceptadas, el de recibidas creció a una tasa de $1.52 \%$, mientras que el de aceptadas creció a una tasa de $0.04 \%$. Particularmente en 2017, Estados Unidos y Canadá recibieron 317,639 solicitudes de refugio ( $16.98 \%$ del total mundial) y aceptaron 39,618 (8.23\% del total mundial).

La gráfica 2 señala la participación y tendencias de las solicitudes recibidas y aceptadas durante 2000-2017 en los países de Norte y Centroamérica. En lo que va del presente siglo, en términos relativos, Estados Unidos y Canadá tienen el mayor número de solicitudes recibidas y aceptadas de la región $(90 \%$ del tamaño total entre 2000 y 2017). En este mismo período, Estados Unidos y Canadá recibieron un $9.77 \%$ del total de solicitudes recibidas en el mundo y de ellas aceptaron $15.49 \%$. En cambio, en relación con lo ocurrido en el continente, recibieron y aceptaron más de un $90 \%$ del total de las solicitudes: $90.30 \%$ del total de recibidas y $92.95 \%$ del de aceptadas. Sin embargo, en 2016 y 2017, los países de América Latina han ganado un leve protagonismo con porcentajes cercanos al $10 \%$.

Gráfica 2. Distribución de solicitudes recibidas, aceptadas y porcentaje de aprobaciones de refugio en Norte y Centroamérica, 2000-2017

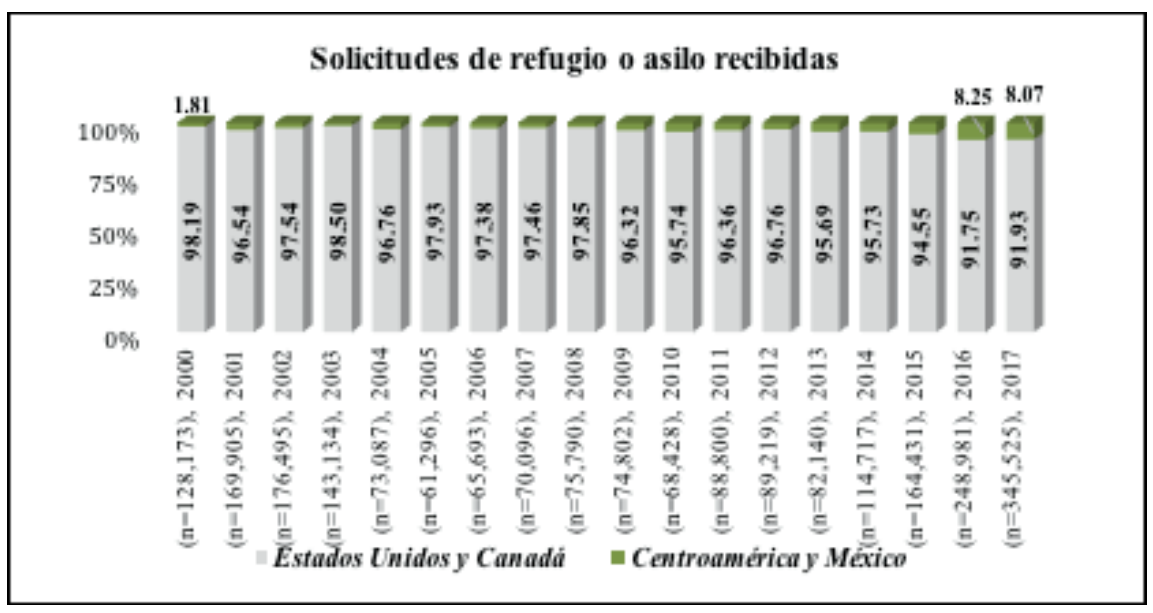




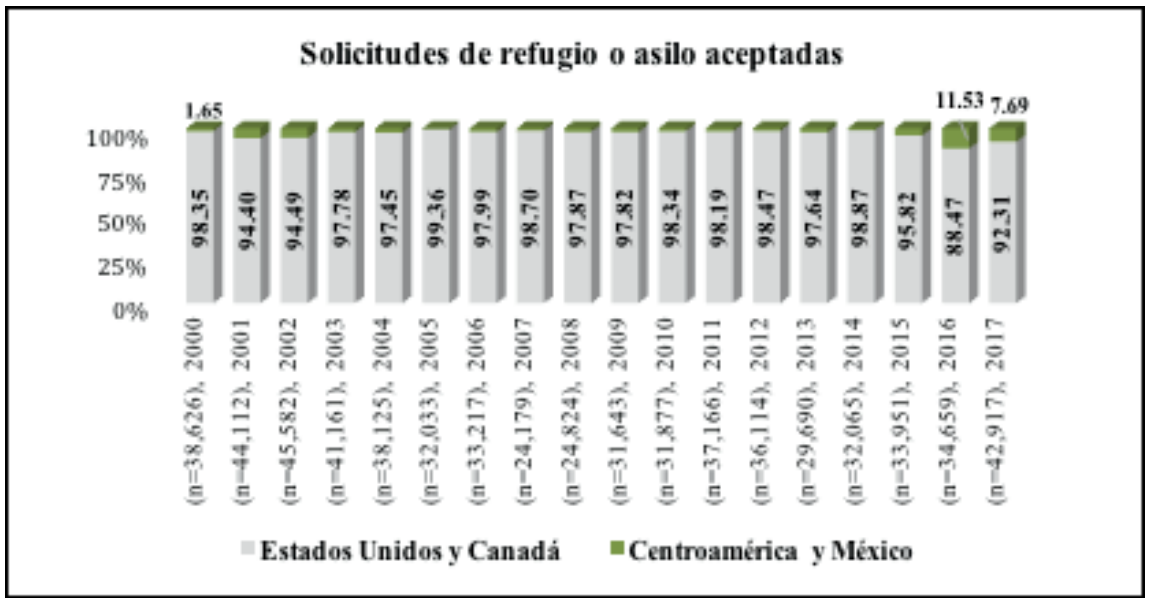

Nota: Se calculó el número de solicitantes de refugio para el periodo 20002017, para todos los países reportados en la ACNUR.

Fuente: Alto Comisionado de Naciones Unidas para los Refugiados (ACNUR). Population Statistics, Time Series. Disponible en: http://popstats.unhcr.org/en/ persons_of_concern

Al analizar el comportamiento individual por cada país, la gráfica 3 indica que, para los Estados Unidos, 2009 fue el año que se recibió el menor número de solicitudes $(38,080)$ y 2016 fue el que se recibió el mayor número $(265,067)$. En el caso de Canadá, 2017 fue el año de mayor cantidad de solicitudes (52,572), mientras que 2013 fue el de menor número de las mismas $(10,356)$. Estos datos señalan la importancia absoluta de las solicitudes recibidas por Estados Unidos comparadas con las de Canadá. Sin embargo, desde una perspectiva histórica, 2017 se sitúa como el año con mayor número de solicitudes. Desde una escala global, en 2017, los Estados Unidos recibió el $14.17 \%$ de las solicitudes en todo el mundo y $83.45 \%$ en la región de Norteamérica, mientras que Canadá recibió tres de cada cien solicitantes de asilo y $16.55 \%$ en el continente. Los principales países de origen fueron Nigeria, China y Paquistán. 

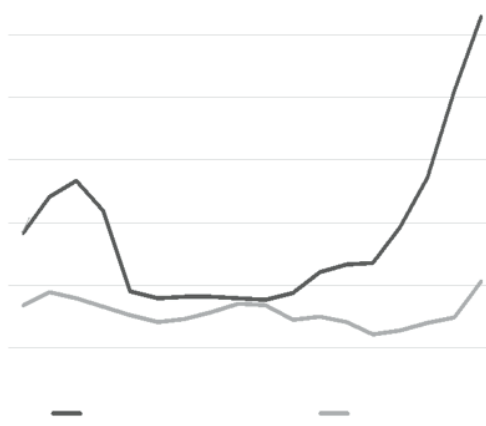

Nota: Se calculó el número de solicitantes de refugio para el periodo 20002016, para todos los países reportados en la ACNUR.

Fuente: Alto Comisionado de Naciones Unidas para los Refugiados (ACNUR). Estadísticas de población. Series de tiempo. Disponible en: http://popstats. unhcr.org/en/persons_of_concern

De 2000 a 2017 el número de solicitudes de refugio recibidas en la región varió (Gráfica 4). De manera general, para estos años, la región recibió un total de 101,096 solicitudes de refugio $(0.51 \%$ del total mundial y $4.51 \%$ del continental). Costa Rica y México fueron los países que recibieron el mayor número de solicitudes. Sin embargo, en 2005, Costa Rica no recibió solicitud de refugio alguna. Finalmente, El Salvador fue el país que recibió menos solicitudes: $310(0.33 \%$ del total en la región); en 2005, apenas recibió una solicitud.
Durante 2017 la región centroamericana recibió un total de 27,886 solicitudes de refugio $(1.49 \%$ del total mundial y $8.07 \%$ del continental). En este año, México fue el país que recibió el mayor número de solicitudes: 14.528 (52.09\% del total regional y $5.20 \%$ del continental). Como se observó en el apartado anterior los principales países de origen fueron Honduras, El Salvador y Guatemala.

Costa Rica fue el segundo país con el mayor número de solicitudes recibidas durante 2017: 7,092 (25.43\% del total regional y $2.54 \%$ del continental). Los principales 
países de origen fueron El Salvador, Venezuela y Colombia. Por su parte, Panamá fue el tercer país con mayor número de solicitudes recibidas durante 2017: 5,557 (19.93\% del total regional y $1.99 \%$ del continental). Los principales países de origen fueron Colombia, Nicaragua y Venezuela.

En otro sentido, algunos países centroamericanos comparten realidades sociales y estructurales que inciden en el flujo de los solicitantes de refugio (Martínez, 2016). Países como El Salvador, Honduras y Guatemala cuentan con escenarios de violencia similares: crimen organizado, extorsión, violencia sexual y violencia de género, violencia contra niños y niñas y adolescentes. Además, enfrentan dificultades socioeconómicas que dificultan la generación de mejores condiciones de vida (ACNUR, 2017).

Las condiciones de deterioro conllevan, entre otras acciones, el desplazamiento forzado de las personas. Los países colindantes de la región reciben, cada vez más, a mayor número de personas solicitantes de refugio (Ibídem). La petición de refugio en Centroamérica tiene un carácter, en la mayoría de los casos, intrarregional. Se trata de una relación entre los países de origen como de asilo en la que comparten retos para garantizar una política regional y nacional que se apegue a los estándares internacionales y en la que se garantice la protección de las personas solicitantes de refugio, así como el cumplimiento de sus derechos humanos.

Con respecto a las solicitudes aprobadas, tanto en Estados Unidos como en Canadá no ha persistido una tendencia definida. En el primer país, 2001, fue el año que se aceptó el mayor número de refugiados $(28,304)$, y en 2008 , aceptaron la menor cantidad con 16,742. Mientras tanto en Canadá, 2003 y 2007 fueron los años de mayor $(17,682)$ y menor $(5,885)$ número de aceptaciones, respectivamente.

En el período de análisis, la región de Centroamérica y México aceptó un total de 27,886 solicitudes de refugio (1.49\% del total mundial y $8.07 \%$ del continental). México fue el país que aceptó el mayor número de solicitudes $(52.09 \%$ del total regional y $5.20 \%$ del continental. Por su parte, Costa Rica fue el segundo país que aceptó el mayor número de solicitudes (34.24\% del total en la región; $0.99 \%$ del continental; y $0.16 \%$ del mundial). Finalmente, Belice fue el país que aceptó menos número de solicitudes: 37 ( $0.21 \%$ del total en la región), tal y como se observa en la gráfica 4. 

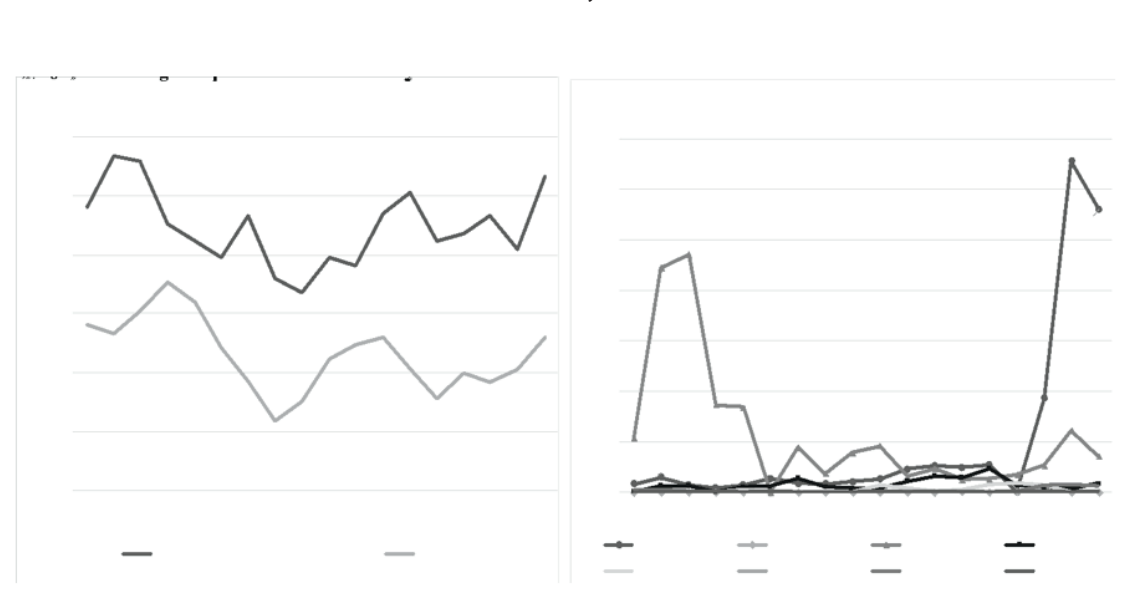

Nota: Se calculó el número de solicitantes de refugio para el periodo 20002016, para todos los países reportados en la ACNUR.

Fuente: Alto Comisionado de Naciones Unidas para los Refugiados (ACNUR). Estadísticas de población. Series de tiempo. Disponible en: http://popstats. unhcr.org/en/persons_of_concern

\section{Solicitantes de refugio y refugiados a nivel mundial}

De 2015 a 2017 la magnitud del flujo de refugiados y solicitantes de refugio, así como de otros flujos migratorios, que cruzaron el Mediterráneo fue inesperada. Más de un millón de personas viajaron principalmente a través del corredor Turquía- Grecia y, en segundo lugar, por la ruta Libia-Italia para arribar a las costas del sur de Europa, continuar más al norte y más al sur en 2015; mientras que otras 350 mil siguieron llegando durante 2016 (Triandafyllidou y Mantanika, 2017).

De acuerdo con la Convención de Ginebra sobre el Estatuto de los Refugiados, un refugiado es una persona que "[...] debido a fundados temores de ser perseguida por motivos de raza, religión, nacionalidad, pertenencia a un determinado 
grupo social u opiniones políticas, se encuentre fuera del país de su nacionalidad y no pueda o, a causa de dichos temores, no quiera acogerse a la protección de su país; o que careciendo de nacionalidad y hallándose, a consecuencia de tales acontecimientos fuera del país donde antes tuviera su residencia habitual, no pueda o, a causa de dichos temores no quiera regresar a él" (ONU: 1951, 2020).
De 2000 a 2017, por cada cien refugiados en el mundo hubo diez solicitudes de refugio recibidas y sólo dos de ellas fueron aceptadas, como se observa en la gráfica 5; lo más probable es que esas ocho personas no aceptadas buscaran otra manera de llegar al destino deseado - a algún otro, engrosando algún otro flujo migratorio internacional.

\section{Gráfica 5. Tendencia mundial del número de refugiados, del número de solicitudes de refugio recibidas y del número de solicitudes aceptadas, 2000-2016}

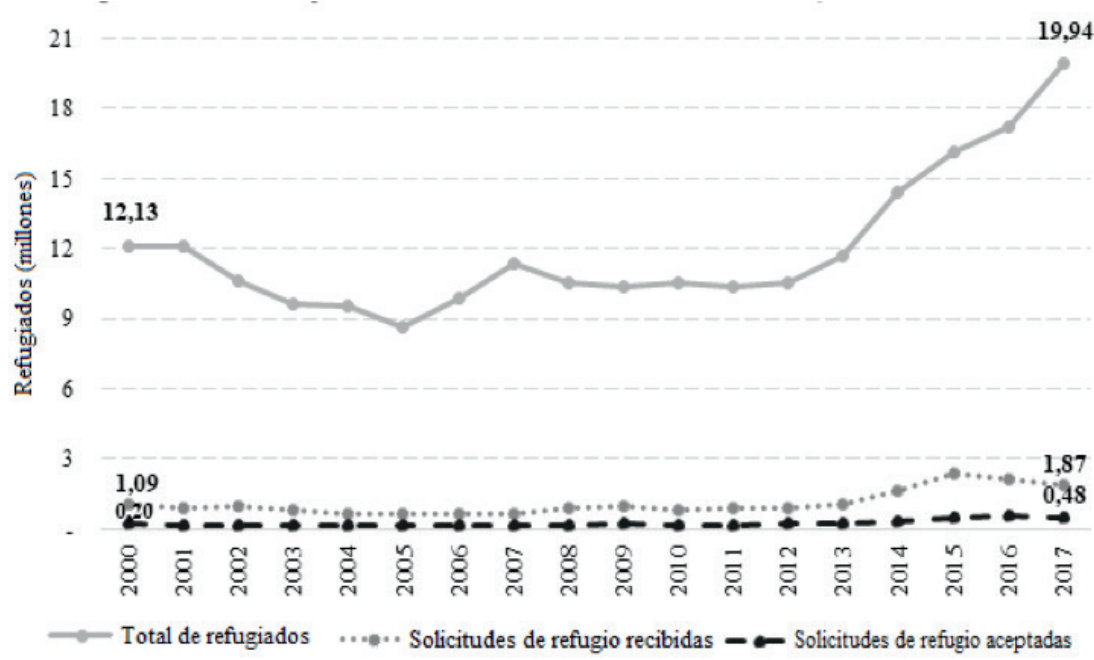

Nota: Se calculó el número de refugiados y de solicitudes de refugio (recibidas y aceptadas) para el periodo 2000-2016, para todos los países reportados en la ACNUR. En el caso del número de refugiados, las cifras también incluyen los casos de personas en situación similar (refugee-like situations).

Fuente: Alto Comisionado de Naciones Unidas para los Refugiados (ACNUR). Estadísticas de población. Series de tiempo. Disponible en: http://popstats. unhcr.org/en/persons_of_concern 
Para el año 2000 hubo 12,129,572 de refugiados bajo el mandato del ACNUR, y para 2017, esta cifra ascendió a 19, 937,581 como ilustra la gráfica 6. Es decir, de 2000 a 2017 el número absoluto de refugiados aumentó en 7, 808,009.

Entre 2000 y 2017, por cada 100 solicitudes de refugio recibidas, un promedio de veinte fueron aceptadas. Para el año 2000 se presentaron 1,093,045 solicitudes de refugio, mientras que en 2017 se presentaron 1,870,164. Es decir, de 2000 a 2017, el número de solicitudes de refugio recibidas aumentó casi un millón, en términos absolutos. Por su parte, para el año 2000 se aceptaron 203,402 solicitudes de refugio. En 2017, en cambio, se aceptaron 481,443. Es decir, de 2000 a 2016, el número de solicitudes de refugio aceptadas aumentó en 278,041, también en valores absolutos.

Para 2017 la distribución geográfica de los países de origen y de asilo de refugiados y de los solicitantes de refugio varió dependiendo del caso. El Cuadro 3 muestra las principales cifras de dicha distribución. En 2000, los seis países con el mayor número de refugiados fueron Irán, Inglaterra Alemania, Estados Unidos y Francia. Mientras, en 2017 sólo se mantuvieron ingresaron en los primeros cinco lugares Italia y Turquía, desplazando a Irán e Inglaterra.
En relación con la distribución geográfica de los países de origen de los solicitantes de refugio y los países que recibieron dichas solicitudes, el Cuadro 4 muestra las principales cifras de dicha distribución para 2000 y 2017. En 2000 los países de nacimiento de los refugiados más comunes fueron Afganistán, Serbia y Kosovo e Iraq. En 2017 permanecen Iraq y Afganistán, y se sumaron Siria y Venezuela.

Los principales países de origen que solicitaron refugio en Europa pertenecen al continente asiático y africano. En Alemania, los países de origen fueron Siria Afganistán e Irán. En Italia, Nigeria y Pakistán y en Francia fueron Albania, Sudán y Afganistán. Mientras que los principales países de origen de los solicitantes de refugio en Estados Unidos fueron El Salvador y México.

En el mundo, en 2017, Asia y África fueron los continentes que albergaron al mayor número de refugiados, mientras que Europa (Alemania, principalmente) y Estados Unidos fueron quienes recibieron el mayor número de solicitudes de refugio. Las principales rutas que han utilizado los solicitantes de asilo hacia Europa se encuentran en el área del mar Mediterráneo. Las tres rutas principales son: Mediterráneo occidental, de África occidental o subsahariana a través de Marruecos hasta España; central, de África oriental u occidental 
pasando por Libia (o Túnez) hasta Italia; y Mediterráneo oriental, desde Asia, Medio Oriente y en ocasiones también desde África oriental por Turquía hasta Grecia (Triandafyllidou y Mantanika: 2017,10); las que llegan

a Estados Unidos tienen en común un país de convergencia, como origen o antesala de prácticamente todos los demás flujos internacionales solicitantes de refugio: México (Centro Latinoamericano y Caribeño de Demografía [CELADE], 2017).

Cuadro 4. Principales países de origen y recepción del mayor número de solicitudes de asilo o refugio recibidas en 2000 y 2017.

\begin{tabular}{|c|c|c|c|c|c|c|}
\hline Año & $\begin{array}{l}\text { Principales } \\
\text { paises } \\
\text { receptores }\end{array}$ & $\begin{array}{l}\text { solicitudes } \\
\text { de asilo } \\
\text { o refugio } \\
\text { recibidas }\end{array}$ & $\begin{array}{l}\text { Porcentaje } \\
\text { total de } \\
\text { refugiados } \\
\text { en el mundo }\end{array}$ & $\begin{array}{c}\text { Principales paises } \\
\text { de origen }\end{array}$ & $\begin{array}{l}\text { Solicitudes } \\
\text { de asilo } \\
\text { o refugio } \\
\text { recibidas }\end{array}$ & $\begin{array}{c}\text { Porcentaje } \\
\text { de } \\
\text { solicitudes } \\
\text { recibidas } \\
\text { en cada } \\
\text { país } \\
\text { receptor } \\
\text { (\%) }\end{array}$ \\
\hline \multirow{6}{*}{2000} & Iran & 245,854 & 22.49 & Afghanistan & 245,854 & 100 \\
\hline & Inglaterra & 128,425 & 11.75 & $\begin{array}{l}\text { Varios / Sin } \\
\text { información Iraq } \\
\text { Siri Lanka }\end{array}$ & $\begin{array}{l}59,380 \\
7,475 \\
6,395\end{array}$ & $\begin{array}{l}46.24 \\
5.82 \\
4.98\end{array}$ \\
\hline & Alemania & 117,648 & 10.76 & $\begin{array}{l}\text { Serbia y Kosovo } \\
\text { Turqui } \\
\text { Iraq }\end{array}$ & $\begin{array}{l}28,046 \\
14,355 \\
12,023\end{array}$ & $\begin{array}{l}23.84 \\
12.2 \\
10.22\end{array}$ \\
\hline & $\begin{array}{l}\text { Estados } \\
\text { Unidos de } \\
\text { América }\end{array}$ & 91,595 & 8.38 & $\begin{array}{l}\text { China } \\
\text { México } \\
\text { Haití }\end{array}$ & $\begin{array}{l}14,188 \\
9,279\end{array}$ & $\begin{array}{l}15.49 \\
10.13 \\
9.98\end{array}$ \\
\hline & Francia & 59,899 & 5.48 & $\begin{array}{l}\text { China } \\
\text { Turquia } \\
\text { Malí }\end{array}$ & $\begin{array}{l}9,674 \\
5,585 \\
5,555\end{array}$ & $\begin{array}{l}16.15 \\
9.32 \\
9.27\end{array}$ \\
\hline & $\begin{array}{l}\text { Total de } \\
\text { refugiados }\end{array}$ & $1,093,034$ & 58.87 & $\begin{array}{l}\text { Afghanistan } \\
\text { Varios / Sin } \\
\text { información } \\
\text { Serbia y Kosovo } \\
\text { Iraq }\end{array}$ & $\begin{array}{l}291,283 \\
87,038 \\
64,413 \\
62,310\end{array}$ & $\begin{array}{l}26.65 \\
7.96 \\
5.89 \\
5.7\end{array}$ \\
\hline
\end{tabular}




\begin{tabular}{|c|c|c|c|c|c|c|}
\hline \multirow{6}{*}{2017} & $\begin{array}{l}\text { Estados } \\
\text { Unidos de } \\
\text { América }\end{array}$ & 265,067 & 14.17 & $\begin{array}{l}\text { El Salvador } \\
\text { Guatemala } \\
\text { Venezuela }\end{array}$ & $\begin{array}{l}49,726 \\
35,546 \\
30,228\end{array}$ & $\begin{array}{l}18.76 \\
13.41 \\
11.4\end{array}$ \\
\hline & Germany & 222,565 & 11.9 & $\begin{array}{l}\text { Siria } \\
\text { Iraq } \\
\text { Afghanistan }\end{array}$ & $\begin{array}{l}50,422 \\
23,605 \\
18,282\end{array}$ & $\begin{array}{l}22.65 \\
10.61 \\
8.21\end{array}$ \\
\hline & Francia & 153,814 & 8.23 & $\begin{array}{l}\text { Albania } \\
\text { Haití } \\
\text { Afghanistan }\end{array}$ & $\begin{array}{l}19,609 \\
10,824 \\
8,083\end{array}$ & $\begin{array}{l}12.75 \\
7.04 \\
5.26\end{array}$ \\
\hline & Turquia & 126,850 & 6.78 & $\begin{array}{l}\text { Afghanistan } \\
\text { Iraq } \\
\text { Iran }\end{array}$ & $\begin{array}{l}67,352 \\
44,523 \\
9,989\end{array}$ & $\begin{array}{l}53.1 \\
35.1 \\
7.87 \\
\end{array}$ \\
\hline & Italia & 126,375 & 6.76 & $\begin{array}{l}\text { Nigeria } \\
\text { Bangladesh } \\
\text { Pakistan }\end{array}$ & $\begin{array}{l}25,094 \\
12,183 \\
9,373\end{array}$ & $\begin{array}{l}19.86 \\
9.64 \\
7.42 \\
\end{array}$ \\
\hline & $\begin{array}{l}\text { Total de } \\
\text { refugiados } \\
2017\end{array}$ & $1,870,033$ & 47.84 & $\begin{array}{l}\text { Afghanistan } \\
\text { Iraq } \\
\text { Siria } \\
\text { Venezuela }\end{array}$ & $\begin{array}{l}149,824 \\
127,849 \\
124,643 \\
112,328\end{array}$ & $\begin{array}{l}8.04 \\
6.84 \\
6.67 \\
6.01 \\
\end{array}$ \\
\hline
\end{tabular}

Nota: El número de refugiados incluyen los casos de personas en situación similar (refugee-like situations). Los porcentajes de refugiados, respecto del total de refugiados en 2016, no suman 100 porque la lista mencionada sólo incluye a los 5 principales países de asilo.

Fuente: Alto Comisionado de Naciones Unidas para los Refugiados (ACNUR). Estadísticas de población. Series de tiempo. Disponible en: http://popstats. unhcr.org/en/persons_of_concern

\section{Consideraciones finales}

De 2000 a 2017 la población de refugiados, las poblaciones que lo solicitan y la respuesta de los gobiernos han tenido comportamientos distintos. Ello genera efectos diversos en los países, las regiones y en los continentes, sean de origen o de asilo de la petición de refugio. Ver el valor relativo de un proceso frente a otros escenarios ayuda a justipre- ciar el significado de los procesos particulares y a evitar apreciaciones que los sobredimensionan y llegan a generar actitudes sociales y medidas proteccionistas muy próximas a la intolerancia y exclusión.

De 2000 a 2017, por cada 100 refugiados hubo diez solicitudes recibidas y sólo dos de ellas fueron 
aceptadas. Aunque hay convenciones y protocolos internacionales, casi todos ellos firmados y ratificados por la mayoría de los Estados miembro de Naciones Unidas, lo cierto es que en la operación los países con mayor demanda de refugio se guían por criterios diversos y consideraciones locales. De ahí que. al analizar series estadísticas. se observa cómo se van presentando brechas crecientes entre el total de solicitudes recibidas y el total de aceptadas, ambas en un contexto de subregistro debido a la conjugación de muy diversos factores políticos, sociales, culturales, administrativos y de seguridad nacional, entre otros. Mas, en esa diversidad, una cosa queda clara: cada vez crece más el flujo de solicitantes de refugio y, cada vez más, se reduce el total de solicitantes que logran el estatuto de refugiado como lo hace ver distintos organismos y analistas (Amnistía Internacional. 2018; ACNUR, 2020; Asylum Access México. 2019; Centro de Derechos Humanos Fray Matías de Córdova y El Colegio de la Frontera Norte, 2020; Human Rights First. 2017; Kerwin, H., 2018; Rea Granados, S. A., 2016; y Sin Fronteras I. A. P., 2016.)

La relación anterior sugiere que el desplazamiento forzado de personas tiene un efecto muy significativo en lo social y en lo individual. (A la vez, es importante saber qué pasa con la población solicitante de refugio que es rechazada, pues es un volumen importante en que se conjugan distintas problemáticas sociales que trascienden las fronteras nacionales de afectados, organismos humanitarios, agencias internacionales, redes delictivas y gobiernos.) Resulta conveniente revisar las tendencias futuras de los solicitantes de refugio y generar una mayor coordinación institucional y política entre los países de origen y asilo de dichos solicitantes, a fin de garantizarles protección y el cumplimiento de sus derechos humanos.

En 2017, a nivel mundial, Asia -en países como Turquía, Líbano, Paquistán e Irán- albergó a la mayoría de refugiados (36.14\%). Los principales países de origen fueron Siria (con 22.82\%) y Afganistán (con 13.4\%). Por su parte, Europa recibió el mayor número de solicitudes de refugio en países como Alemania (35.82\%), Italia (5.90\%) y Francia (5.70\%). Los principales países de origen que solicitaron refugio en Europa pertenecen a Asia y África: en Alemania, los países de origen fueron Siria Afganistán e Irán; en Italia fueron Nigeria y Pakistán; y en Francia fueron Albania, Sudán y Afganistán.

La situación de los países de América del Norte, México y Centroamérica es un tanto diferente en relación con la cantidad de solicitudes presentadas, las aceptadas y los países de origen de los solicitantes. De 2000 a 2017, América recibió $10.82 \%$ del total de solicitudes 
recibidas en el mundo. Durante ese mismo periodo, el continente aceptó un $16.67 \%$ del total mundial. Estados Unidos y Canadá, por su parte, recibieron un $9.77 \%$ del total mundial y aceptaron un $15.49 \%$ de ese mismo total. En cambio, en relación con lo ocurrido en el continente, Estados Unidos y Canadá recibieron y aceptaron más de un $90 \%$ del total de las solicitudes: $90.30 \%$ del total de las recibidas en el continente y $92.95 \%$ del total de las aceptadas en el continente. Es decir, Estados Unidos y Canadá tienen un peso relativo muy importante en el continente en materia de refugio, pero no así respecto al mundo.

Por su parte, Centroamérica, también de 2000 a 2017, representó no más de un $3.5 \%$ de los solicitantes de refugio en el continente y apenas un $0.5 \%$ a nivel mundial. Específicamente, México recibió $29.39 \%$ del total de solicitudes en la región, que representa $1 \%$ del total continental y $0.11 \%$ del mundial. Asimismo, México aceptó un 34.24\% del total de solicitudes en la región, un $0.99 \%$ del continental y $0.16 \%$ del mundial. Se puede decir que estas solicitudes responden más a un movimiento intrarregional que intercontinental. Durante 2016, por ejemplo, Centroamérica recibió un total de 20,383 solicitudes de refugio: $0.98 \%$ del total de solicitudes en el mundo y $7.38 \%$ del continental. México fue el país que mayor número de solicitudes recibió:
42.84\% del total regional, $3.16 \%$ del continental y $0.42 \%$ del mundial. Los principales países de origen fueron Honduras, El Salvador y Guatemala.

Un fenómeno similar se puede observar en países como Costa Rica y Panamá. Durante 2016, Costa Rica fue el segundo país con mayor porcentaje de solicitudes recibidas: 28.62\% del total regional, $2.11 \%$ del continental y $0.28 \%$ del mundial. Los principales países de origen fueron El Salvador y Colombia. Panamá, por su parte, recibió a un $16.96 \%$ del total de solicitudes a nivel regional (1.25\% del continental y $0.16 \%$ del mundial) y tuvo como principales países de origen a Colombia y Nicaragua. Es decir, si bien de 2000 a 2016, a nivel regional, las cifras en materia de solicitudes de refugio y de refugiados son significativas, a nivel continental se tiene un efecto no mayor a $11 \%$ en materia de solicitudes de refugio recibidas y no mayor a un $17 \%$ de solicitudes de ellas aceptadas. Sin embargo, a nivel mundial este efecto es muy menor: el porcentaje de solicitudes recibidas y aceptadas no supera el $0.5 \%$ del total de las recibidas y aceptadas a nivel mundial.

Durante 2017 las solicitudes de refugio en México tuvieron un aumento importante en relación con 2016: para 2017, se recibió un total de 14,596 solicitudes (59.82\% más que las recibidas en 2016). Sin embargo, para 2017 el total de 
aceptadas disminuyó en $58.49 \%$ en relación con el total aceptadas en 2016 (3,260). Por otro lado, la cifra de solicitudes de niñas, niños y adolescentes aceptadas no fue muy elevada (36), aunque invita a revisar los protocolos de atención y protección para este grupo poblacional, sin la presión de cifras altas, pues existe el alto riesgo de que, al aceptar un número bajo de solicitudes, haya una transferencia de los rechazados a otro flujo, con lo que, en un caso extremo, la reducción administrativa de un flujo se torne en un engrosamiento social de otro flujo migratorio internacional.

Estas cifras invitan a una revisión de los siete compromisos que adquirió México, en materia de refugio, durante el $71^{\circ}$ período de sesiones de la Asamblea General de la ONU:

1. Fortalecer el diálogo con autoridades de países de la región centroamericana, así como con Estados Unidos y Canadá para actuar de manera corresponsable.

2. Promover la inclusión socioeconómica de quienes son reconocidos como refugiados.

3. Fortalecer los procedimientos de elegibilidad con base en estándares internacionales.
4. Reforzar la presencia de la Comisión Mexicana de Ayuda a Refugiados en aquellos sitios donde se registra un mayor número de solicitudes.

5. Impulsar alternativas para evitar la detención administrativa de los solicitantes de refugio, en particular de niñas y niños.

6. Realizar campañas informativas para difundir el derecho a solicitar refugio, con el apoyo de ACNUR y OSC.

7. Aplicar protocolos que identifiquen las necesidades de protección internacional para niñas, niños y adolescentes no acompañados.

Estas medidas pueden constituir buenas prácticas aplicables a los solicitantes centroamericanos de refugio, en particular, y al resto de los flujos migratorios centroamericanos de paso por México, si se incrementa el número de peticiones aceptadas, pues reduciría la transferencia de quienes son rechazados al flujo en tránsito; un flujo altamente susceptible de recibir daños mayores, como secuestros individuales y colectivos (Observatorio Nacional Ciudadano [ONC], 2014).

¿Desde dónde es pertinente analizar lo que sucede en Centroamérica en materia de solicitantes de refugio? Los datos invitan a una reflexión 
y propuesta de líneas de acción desde una perspectiva regional (Centroamérica, México y Estados Unidos) (Pew, 2017). El flujo intrarregional de solicitantes de refugio implica una relación entre los países de origen, tránsito y de asilo en la que, por su cercanía geográfica y por las situaciones estructurales que enfrentan, se comparten retos para garantizar una política regional y nacional que se apegue a los estándares internacionales y en la que se garantice la protección de las personas migrantes y el cumplimiento de sus derechos humanos. En este sentido, es importante revisar y comparar la congruencia que existe entre los discursos oficiales y las políticas reales que han adoptado los países de la región para generar un discurso y un marco de acción, en común, que reconcilie la solidaridad con el orden público de sus naciones (Triandafyllidou, 2017).

Aunque la tendencia actual de solicitudes de refugio de Centroamérica es distinta a la tendencia mundial en términos reales, en términos procedimentales e interinstitucionales, existen importantes similitudes entre esta región y la Unión Europea - principal destino de solicitantes de refugio a nivel mundial: ambas regiones comparten, en su interior, características económicas y sociales que las hacen destinos principales de los solicitantes de refugio de sus países vecinos; en ambas regiones se han visto incrementadas las cifras de solicitudes de refugio recibidas; en ambas regiones los flujos migratorios convergen en tiempo y espacio, por lo que resulta difícil aplicar normativas y políticas migratorias particulares, por tipo de flujo; y, sobre todo, ambas regiones han requerido atender el fenómeno migratorio desde una visión multilateral. A partir de estas similitudes, las experiencias de la Unión Europea, en materia migratoria y con los solicitantes de refugio, pueden ser un campo de referencia sobre el cual Centroamérica pueda coordinar sus esfuerzos para atender el fenómeno de la migración.

De acuerdo con Arango et al. (2017), y con base en las experiencias de la Unión Europea, las políticas orientadas a atender el fenómeno de la migración deben considerar una mayor solidaridad en la distribución de responsabilidades entre Estados para proteger y atender a los refugiados y solicitantes de refugio. En este sentido, el plan de acción conjunto Unión Europea -Turquía de noviembre de 2015 y su Declaración, en marzo de 2016, es un buen ejemplo de una política de colaboración entre la Unión Europea y terceros países, generalmente países de tránsito, en el sistema de control migratorio europeo (Arango et al., 2017; Triandafyllidou y Mantanika, 2017). A reserva de considerar sus limitaciones y especificaciones, se trata de un acuerdo que mejoró el nivel de involucramiento de la Unión 
Europea con los países de tránsito y de origen.

Es importante considerar que las medidas que se promuevan en la región norte-centroamericana (Centroamérica, México y Estados Unidos) deben partir del hecho de que la distinción entre solicitantes de refugio - personas que escapan a la persecución, al conflicto, la violencia y la inseguridad-y migrantes en tránsito irregular se vuelve cada vez más inadecuada para atender por parte de los Estados los flujos internacionales de población. En este sentido, es altamente recomendable generar políticas migratorias multilaterales que, en coordinación, atiendan y protejan a los solicitantes de refugio y al migrante internacional en general. Es decir, dada la tendencia al alza de solicitantes de refugio es indispensable que la región mencionada genere políticas migratorias con un enfoque más amplio que incluya no solamente el control de sus fronteras, sino una nueva gestión del refugio y de la migración laboral ((Triandafyllidou y Mantanika: 2017), entre otras.

La realidad suele ir más rápido que la adecuación de las leyes y su aplicación consecuente. En el caso de México, de aquel lejano año 2000, en que sólo fueron reconocidos 79 de 277 solicitantes de refugio, pasar a 2,806 reconocidos de 14,528 solicitantes da margen a distintas interpretaciones. La más mencionada en ámbitos gubernamentales y algunos sociales es la del crecimiento exponencial, con base en los números relativos, que son innegables. De ahí la percepción de que México está siendo "invadido" por centroamericanos que, en abundancia de temores, provienen de países con altas tasas de violencia como son Honduras y Guatemala.

Frente a esa percepción importa, como se ha argumentado en este texto: 1) Hay una tendencia mundial de crecimiento de los flujos solicitantes de refugio; 2) hay un conjunto de disposiciones oportunamente firmadas y ratificadas por los Estados miembro de Naciones Unidas para la protección de los refugiados, que no debieran ser obstaculizadas por criterios de aplicación discrecional o por trabas administrativas; unos y otras van en sentido contrario a la protección signada. Una aplicación selectiva del refugio da lugar, de manera inmediata y unívoca, como ya se refería en párrafos anteriores, a que esos migrantes engrosen alguno de otros flujos migratorios en curso, conformando flujos mixtos que devienen problemas más complejos para su debida atención por parte de las autoridades migratorias. Por otra parte, 14,528 solicitantes de refugio, aún en el caso extremo de que a todos les fuera reconocido el estatuto de refugiado, y dada su dispersión en el territorio nacional, serían fácilmente absorbidos por una población nacional superior a 
120 millones de mexicanos. El gobi- humanitaria sin el peso de las cifras, erno entrante en diciembre de 2018 y en plena armonía con las disposipuede, en los seis años que dura su ciones internacionales en materia de mandato, desarrollar una política refugio.

\section{Referencias bibliográficas}

- Amnistía Internacional. (2018). Ignoradas y sin protección. La mortal devolución de personas centroamericanas solicitantes de asilo desde México. Obtenido de https://www.amnesty.org/download/Documents/ AMR4176022018SPANISH.PDF

- Alto Comisionado de las Naciones Unidas para los Refugiados México. (2020). ¿Cómo solicitar la condición de refugiado en México? Obtenido de https://help.unhcr.org/mexico/solicitando-la-condicion-de-refugiado/ como-solicitar-la-condicion-de-refugiado-en-mexico/

- Alto Comisionado de Naciones Unidas para los Refugiados (ACNUR). Population Statistics, Time Series. Disponible en: http://popstats.unhcr. org/en/persons_of_concern

- Alto Comisionado de la ONU para Refugiados (ACNUR). El Salvador, Honduras y Guatemala. Disponible en: http://www.acnur.org/dondetrabaja/america/el-acnur-en-america-central-y-mexico/el-salvadorhonduras-y-guatemala/

- Arango, J. et al. (2017). La migración en el ojo del huracán. Anuario CIBOD de la inmigración 2017. CIBOD, Barcelona.

- Asylum Access México (2019). El Instituto Nacional de Migración viola los derechos humanos de una mujer que por segunda ocasión solicita asilo en México. Obtenido de https://asylumaccess.org/el-instituto-nacionalde-migracion-viola-los-derechos-humanos-de-una-mujer-que-porsegunda-ocasion-solicita-asilo-en-mexico/

- Centro de Derechos Humanos Fray Matías de Córdova y El Colegio de la Frontera Norte. (2020). Vulnerabilidad y precariedad en la frontera sur de México. La encuesta de derechos humanos de migrantes y solicitantes de refugio en Tapachula, Chiapas. 2018-2019. Obtenido de https:// observatoriocolef.org/wp-content/uploads/2020/02/INFORME-CDHFMCCOLEF-17feb2020.pdf

- Centro Latinoamericano y Caribeño de Demografía (Celade) (2017). "Informe preliminar de la reunión regional latinoamericana y caribeña de expertas y expertos en migración internacional. Preparatoria del Pacto 
Mundial para una migración segura, ordenada y regular". Santiago de Chile, 30 y 31 de agosto de 2017.

- Comisión Mexicana de Ayuda a Refugiados (Comar). Estadísticas 2017.

- Congreso de la Unión de Estados Unidos Mexicanos. (2014). Ley sobre Refugiados, Protección Complementaria y Asilo Político. Obtenido de http:// www.diputados.gob.mx/LeyesBiblio/pdf/LRPCAP_301014.pdf

- Congreso de la Unión de los Estados Unidos Mexicanos (2012). Reglamento de la Ley Sobre Refugiados y Protección Complementaria. Obtenido de http://www.diputados.gob.mx/LeyesBiblio/regley/Reg_LRPC.pdf

- Congreso de la Unión de los Estados Unidos Mexicanos. (2017). Ley de Migración, 2011, y reformas posteriores. Obtenido de http://www. diputados.gob.mx/LeyesBiblio/ref/Lmigra.htmlDeclaración de Cartagena sobre Refugiados de 1984. (2020). Obtenido de https://www.acnur. org/5b076ef14.pdf

- Human Rights First (2017). Dangerous Territory Mexico Still Not Safe for Refugees. Obtenido de https://www.humanrightsfirst.org/resource/ dangerous-territory-mexico-still-not-safe-refugees

- ITAM (2014). Migración Centroamericana en tránsito por México hacia Estados Unidos: diagnóstico y recomendaciones. (México: ITAM).

- Kerwin, H. (2018). The Mexican Asylum System in Regional Context. Maryland Journal of International Law, 33 (1), pp. 290-312.

- Martínez, Óscar (2010). Los migrantes que no importan. Barcelona: Icaria. (2016). Una historia de violencia. Vivir y morir en Centroamérica. México: Penguin Random House.

- ONC. (2014) Seguridad Justicia y Legalidad. Análisis integral del secuestro en México. Cómo entender esta problemática. México.

- Organización de las Naciones Unidas. Convención de Ginebra sobre el Estatuto de los Refugiados de 1951. (2020). Obtenido de https://eacnur. org/files/convencion_de_ginebra_de_1951_sobre_el_estatuto_de_los_ refugiados.pdf

- OIM (2015). Informe sobre las migraciones en el mundo 2015. Ginebra: OIM.

- Pew Research Center (2017). "Rise in U.S. Immigrants from El Salvador, Guatemala and Honduras Outpaces Growth from Elsewhere. Lawful and unauthorized immigrants increase since recession". 
- Rea Granados, S. A. (2016). Retos actuales en la implementación de la ley sobre refugiados y protección complementaria en México: identificación, admisión y acceso al procedimiento de asilo. Anuario Mexicano de Derecho Internacional, 16, pp. 373-348.

- Secretaría de Gobernación (Segob) (2017). Estadísticas Migratorias. Síntesis 2017, México: Segob.

- Sin Fronteras I. A. P. (2016). Evolución y retos del Asilo en México. 20 años de asistencia legal e incidencia por las personas refugiadas. Obtenido de http:// sinfronteras.org.mx/asiloporderecho.sinfronteras.org.mx/wp-content/ uploads/2016/09/InformeAsilo_2016_WEB.compressed.pdf

- Trejo P., A. P. y Suárez, S. S. (2016) Los centroamericanos y el refugio en México. Informe Obimid. Observatorio Iberoamericano sobre Movilidad Humana, Migraciones y Desarrollo, Madrid:Universidad Pontificia de Comillas.

- Triandafyllidou, A. (2017). "A 'Refugee Crisis' Unfolding: 'Real' Events and Their Interpretation in Media and Political Debates", Journal of Immigrant \& Refugee Studies, Vol. 16:1-2, 198-216.

- Triandafyllidou, A. y Mantanika, R. (2017). “Emergencia de refugiados en el Mediterráneo: evaluación de las respuestas políticas de la Unión Europea”, Migración y Desarrollo, Vol. 15 (No. 28), 7-39.

\section{Notas}

1. Hasta agosto de 2018, el número de personas extranjeras documentadas como residentes permanentes por reconocimiento de refugio en el país fueron 2,146. A falta de la información del último cuatrimestre del año, esta cifra ha incrementado notablemente con respecto a 2017. (UPM y Segob, 2018)
2. Las cifras de ACNUR y Comar para el año 2017 no coinciden. Esto puede estar relacionado con el hecho de que la información de la primera fuente es provisional. 